\title{
I mpact of chemotherapy-induced neutropenia on survival in patients with breast, ovarian and cervical cancer: a systematic review
}

\author{
Ramez Nassef Eskander, Krishnansu Sujata Tewari \\ Division of Gynecologic Oncology, Department of Obstetrics and Gynecology, University of California at Irvine, USA \\ Correspondence: Krishnansu Sujata Tewari. Address: Department of Obstetrics and Gynecology, Division of \\ Gynecologic Oncology, University of California Irvine, CA, USA. Telephone: 949-813-1517. Fax: 17-144-566-632. \\ E-mail: ktewari@uci.edu
}

Received: April 25, 2012

Accepted: July 16, 2012

Published: September 1, 2012

DOI : $10.5430 /$ jhm.v2n3p63

URL: http://dx.doi.org/10.5430/jhm.v2n3p63

\begin{abstract}
Background: Recent advances in chemotherapy administration, including targeted therapies and dose-dense scheduling have led to an increased incidence of neutropenia. Chemotherapy-induced neutropenia has been shown to be associated with improved treatment outcomes in various solid tumor types. We looked to summarize the relationship between chemotherapy-induced neutropenia and survival in patients with breast, ovarian and cervical cancer and describe future directions of research.

Methodology/Principle findings: A comprehensive PUBMED literature search was conducted using the key words "solid tumor", "breast cancer”, "ovarian cancer”, “cervical cancer”, "endometrial cancer”, in combination with “chemotherapy”, "neutropenia”, "survival”, “disease recurrence” and "prognosis”. The search was also guided through a review of the reference lists of original and review articles. Published papers included in the review met the following criteria: patients with breast, ovarian, endometrial or cervical cancer treated with chemotherapy; prospective and retrospective studies, both randomized and cohort designs, evaluating impact of neutropenia or leukopenia on disease outcome. Eleven studies met the inclusion criteria. Sample size ranged from 103-750 subjects. The majority of included studies were conducted in breast cancer patients (7 of 11). No studies related to endometrial cancer were identified. Outcome measures included overall survival, progression free survival and distant disease free survival. All studies were retrospective in nature. Of the 11 identified studies, 9 suggested that the occurrence of chemotherapy-induced neutropenia was associated with improvement in oncologic outcome.
\end{abstract}

Conclusions/Significance: Evaluation of the impact of chemotherapy-induced neutropenia on outcomes in patients with breast, ovarian and cervical cancer is warranted utilizing prospectively collected data from patients enrolled in clinical trials.

\section{Key words}

Neutropenia, Leukopenia, Myelosupression, Breast cancer, Ovarian cancer, Cervical cancer, Survival, Disease progression, Disease recurrence 


\section{Introduction}

In 2012 there will be an estimated 1,638,910 new cancer cases in the United States, with 577,190 deaths ${ }^{[1]}$. In women, two of the most commonly affected sites identified include the genital system, and the breast ${ }^{[1]}$. Recently, interest in the impact of neutropenia on survival during administration of cytotoxic chemotherapy in solid tumors has been under investigation ${ }^{[2]}$. Several published articles have described a positive impact of chemotherapy-induced neutropenia on survival $^{[3-8]}$. Conversely, other studies illustrated no effect, or an adverse impact on survival ${ }^{[9,10]}$.

Traditionally, management of advanced stage solid tumors relies on a combination of surgery followed by chemotherapy with or without radiation. Current cytotoxic chemotherapy regimens are associated with numerous potential toxicities. The incidence of hematologic toxicities, such as neutropenia, associated with a particular regimen varies greatly. The American Society of Clinical Oncology (ASCO) and the European Organization for Research and Treatment of Cancer (EORTC) both released updated guidelines on the use of hematopoietic colony-stimulating factors ${ }^{[11,12]}$. Within both publications, a comprehensive review of chemotherapy regimens used in current practice and the risk of neutropenia were reviewed.

Focusing on breast and ovarian cancer, the practice guidelines outline those regimens with greatest risk of neutropenia. In the adjuvant treatment of breast cancer the risk of grade 4 neutropenia (defined as an absolute neutrophil count (ANC) $<0.5 \times 10^{9} / \mathrm{L}$ ) ranges from $16 \%$ to approximately $90 \%$, with the greatest risk seen in the combination regimen of cyclophosphamide, epirubicin and fluorouracil ${ }^{[11,13]}$. For the treatment of metastatic breast cancer, 1 st line therapies have a greater than $70 \%$ risk of grade 3 or 4 neutropenia. Lastly, carboplatin and paclitaxel, the standard adjuvant regimen for the treatment of ovarian carcinoma, carries a $30-60 \%$ risk of neutropenia ${ }^{[14-16]}$. Given the risk of chemotherapy-induced neutropenia detailed above, investigation into the impact this may have on patient survival is warranted.

Greater than a decade ago, Gurney published an article describing the limitations of body surface area (BSA) dosing ${ }^{[17,18]}$. BSA dosing does not account for the complex process of cytotoxic drug elimination. This leads to an unpredictable variation in effect. Overdosing is easily recognized, but it is possible that unrecognized under-dosing is more common and may occur in $30 \%$ or more of patients receiving standard regimens. Those patients who are inadvertently under-dosed are at risk of a significantly reduced anticancer effect ${ }^{[19]}$.

In order to better understand the implications of neutropenia on outcome during cytotoxic chemotherapy for the treatment of breast, ovarian and cervical cancer, we looked to review the currently published literature. Given the paucity of data in gynecologic cancers, this review article incorporated findings from the breast cancer literature. Breast cancer and ovarian cancer have been shown to respond to similar cytotoxic agents, as well targeted therapies such as bevacizumab.

\section{Methods}

A comprehensive PUBMED literature search was conducted using the key words "solid tumor”, "breast cancer”, "ovarian cancer”, "cervical cancer", "endometrial cancer” in combination with "chemotherapy”, "neutropenia”, "survival”, "disease recurrence" and "prognosis". The search was also guided through a review of the reference lists of original and review articles. Only articles published in English were reviewed. No studies involving endometrial cancer were identified. Published papers included in the review met the following criteria: patients with breast, ovarian or cervical cancer treated with chemotherapy; prospective and retrospective studies, both randomized and cohort designs, evaluating impact of neutropenia or leukopenia on disease outcome. A total of 368 articles were identified with ultimate exclusion of 357 studies. Eleven studies contained adequate, applicable data for review. Two investigators, KST and RNE, evaluated the included papers and abstracted the pertinent data. The following review summarizes the findings of these previously published articles. 


\section{Results}

\subsection{Breast cancer}

Based on data from numerous cooperative group trials, and meta-analysis, it is evident that multi agent adjuvant chemotherapy improves survival in women with early stage breast cancer. However, there is still disagreement regarding the optimum duration, dose and schedule of therapy. The findings of Wood et al. illustrated that lower doses of cyclophosphamide, adriamycin and 5-fluororuacil were associated with poor survival outcomes ${ }^{[20]}$. In addition, unscheduled dose reductions have been correlated with decreased survival in breast cancer patients treated with chemotherapy. However, some retrospective studies have failed to show a correlation between dose received and therapy efficacy ${ }^{[21]}$. Importantly, limitations in the retrospective calculation of dose-intensity have been identified ${ }^{[22]}$. As an example, the selection of patients with better tolerance to higher doses of chemotherapy may introduce bias into analysis of the impact of dose density in breast cancer patients.

In order to account for this potential confounder, Saarto et al. correlated a biological measure of dose intensity, namely chemotherapy induced neutropenia, with treatment outcome in patients with stage 2 and 3 breast cancer ${ }^{[21]}$. Two hundred and eleven patients were treated with eight cycles of adjuvant chemotherapy comprising cyclophosphamide, doxorubicin and oral ftorafur (CAFt), with and without tamoxifen. The impact of the hematologic toxicity of CAFt on distant disease-free survival (DDFS) and overall survival (OS) was recorded. Dose intensity of all given cycles (DI), dose intensity of the two initial cycles (DI2) and total dose (TD) were calculated separately for all chemotherapy drugs and were correlated with DDFS and OS. The authors demonstrated that patients with a lower leukocyte nadir (defined as $<2 \times 10^{9} / \mathrm{L}$ ) during chemotherapy had a significantly better DDFS and OS ( $p=0.01$ and 0.04 respectively). Dose intensity of the two first cycles also correlated significantly with DDFS $(p=0.05)$ in univariate but not in multivariate analysis, while the leukocyte nadir retained its prognostic value.

This was followed by a retrospective review investigating the impact of hematologic toxicity on survival after adjuvant treatment for breast cancer ${ }^{[23]}$. The authors reviewed the records of 484 patients with breast carcinoma who received adjuvant treatment with cyclophosphamide, methotrexate, and 5-fluorouracil (CMF) at Princess Margaret Hospital between 1980-1990, analyzing the effects of Grade 3 or 4 myelosupression (according to CTCAE criteria) during treatment on outcome. The actuarial survival curves for 227 patients with documented grade 3 or 4 hematologic toxicity was compared to that for 257 patients who underwent at least one interim count not indicating such toxicity. Univariate analysis indicated that patients who experienced toxicity had an improved outcome $(p=0.006)$. Using a Cox proportional hazards model to account for numerous prognostic factors, myelosupression was shown to have a hazard ratio (HR) of 0.77 (95\% CI 0.59-1.00; $p=0.05)$.

Cameron et al., as an extension of the 2 trials described above, investigated the impact of neutropenia during intravenous CMF therapy in patients with operable breast cancer ${ }^{[4]}$. Previous meta-analysis had indicated that the benefits of adjuvant chemotherapy appeared to diminish with increasing age, and the authors attributed this to a potential failure in delivery of drug dose or dose intensity within the older adjuvant breast cancer population. A total of 750 women treated over a 15 -year period at The Edinburgh Cancer Center with the same intravenous CMF regimen were evaluated to identify patient- and treatment-related factors influencing outcome. Grade 4 neutropenia (neutrophil count $<0.5 \times 10^{9} / \mathrm{L}$ ) was documented in $10 \%$ of patients and in $2 \%$ of the total courses administered. Grade 2 or 3 neutropenia was reported in $45 \%$ of patients and $12 \%$ of courses. Patients with grade 4 neutropenia were more commonly older. Of the 76 patients with at least one documented neutrophil count below $0.5 \times 10^{9} / \mathrm{L}$, all but 2 completed 6 cycles of chemotherapy. However, 74 had a dose reduction or treatment delay. Of particular interest was the observation that patients who had grade 2/3 neutropenia had a $10 \%$ absolute survival advantage over those with no neutropenia $(p<0.001)$. This relationship was seen across all patient and tumor categories and remained significant in multivariate analysis. There was no evidence that a lower delivered dose intensity or older age at presentation resulted in a poorer survival. 
In a related study, Poikonen et al studied the association between leukocyte nadir and prognosis in node-positive breast cancer patients without distant metastasis, receiving adjuvant chemotherapy consisting of CMF ${ }^{[24]}$. Three hundred and sixty-eight patients were treated with six cycles of adjuvant CMF. Some patients $(n=60)$ also received tamoxifen. All patients underwent surgery and received radiotherapy to the axillary and supraclavicular lymph nodes and the chest wall. The effect of leukopenia caused by CMF on DDFS and OS was assessed. A low leukocyte nadir during chemotherapy administration was associated with a long DDFS in univariate analysis when tested as a continuous variable (RR 1.3, 95\% CI 1.04-1.64, $p=0.02$ ). However, in a multivariate analysis only the number of affected lymph nodes, tumor size, progesterone receptor status, surgical procedure, age and adjuvant tamoxifen therapy retained prognostic significance, whereas the leukocyte nadir count did not.

Table 1. Trial characteristics: Chemotherapy-induced neutropenia in patients with breast cancer

\begin{tabular}{|c|c|c|c|c|c|c|c|c|}
\hline Primary Author & Year & Study Type & Stage & $\begin{array}{l}\text { Patient } \\
\text { Number } \\
\text { (n) }\end{array}$ & Setting & Treatment & Variable & End-Point \\
\hline Saarto et al. ${ }^{[21]}$ & 1997 & Retrospective & $\begin{array}{l}\text { Stage 2/3 } \\
\text { breast CA }\end{array}$ & 211 & Adjuvant & $\begin{array}{l}\text { Cyclophosphamide }+ \\
\text { doxorubicin }+ \\
\text { ftorafur } \pm \text { chemo/RT } \\
\pm \text { tamoxifen }\end{array}$ & Leukocyte nadir & $\begin{array}{l}\text { Improved DDFS + } \\
\text { OS } \\
(p=0.01 \text { and } 0.04 \\
\text { respectively) }\end{array}$ \\
\hline Mayers et al. ${ }^{[23]}$ & 2001 & Retrospective & $\begin{array}{l}\text { Localized } \\
\text { breast CA }\end{array}$ & 484 & Adjuvant & CMF & $\begin{array}{l}\text { Myelosupressio } \\
\text { n (CTCAE) }\end{array}$ & $\begin{array}{l}\text { HR death }(95 \% \\
\text { CI) } \\
\text { Myelosupression: } \\
0.77 \text { (0.59-1.00) }\end{array}$ \\
\hline Cameron et al. ${ }^{[4]}$ & 2003 & Retrospective & $\begin{array}{l}\text { Invasive } \\
\text { breast CA }\end{array}$ & 750 & Adjuvant & CMF & $\begin{array}{l}\text { Neutropenia } \\
\text { (CTCAE) }\end{array}$ & $\begin{array}{l}\text { Improved OS in } \\
\text { Grade } 2-3 \\
\text { neutropenia } \\
(p<0.001)\end{array}$ \\
\hline Poikonen et al. ${ }^{[24]}$ & 1999 & Retrospective & $\begin{array}{l}\text { T1-4 node } \\
\text { positive } \\
\text { breast CA }\end{array}$ & 368 & Adjuvant & CMF & $\begin{array}{l}\text { Minimum } \\
\text { leukocyte count }\end{array}$ & $\begin{array}{l}\text { Improved DDFS } \\
\text { RR } 1.3(1.04-1.06)\end{array}$ \\
\hline Ishitobi et al. ${ }^{[8]}$ & 2010 & Retrospective & $\begin{array}{l}\text { T2-4 N0-3 } \\
\text { MO breast } \\
\text { CA }\end{array}$ & 103 & Neo-adjuvant & $\begin{array}{l}\text { Epirubicin }+ \\
\text { cyclophosphamide } \pm \\
5-\mathrm{FU} \pm \text { docetaxel }\end{array}$ & Neutropenia & $\begin{array}{l}5 \text { year DDFS rae } \\
\text { No neutropenia: } \\
64 \% \\
\text { Neutropenia: } \\
97 \% \\
(p=0.004)\end{array}$ \\
\hline Han et al. ${ }^{[7]}$ & 2011 & Retrospective & $\begin{array}{l}\text { Stage } 1 / 2 \\
\text { breast CA }\end{array}$ & 355 & Adjuvant & CEF & $\begin{array}{l}\text { Neutropenia } \\
\text { (CTCAE) }\end{array}$ & $\begin{array}{l}\text { HR death (95\% } \\
\text { CI) } \\
\text { Mild neutropenia: } \\
0.434 \\
(0.298-0.634) \\
\text { Severe } \\
\text { neutropenia: } \\
0.640 \text { (0.42-0.975) }\end{array}$ \\
\hline Kumpulainen et al. ${ }^{[25]}$ & 2009 & Retrospective & $\begin{array}{l}\text { Stage 1-3B } \\
\text { breast CA }\end{array}$ & 194 & Adjuvant & CNF; CMF & Leukocyte nadir & $\begin{array}{l}10 \text { year BC } \\
\text { specific survival } \\
\text { Low leukocyte } \\
\text { count: } \\
51 \% \\
\text { High Leukocyte } \\
\text { count: } \\
66 \% \\
(p=0.23)\end{array}$ \\
\hline
\end{tabular}

$\mathrm{CA}$ = cancer; RT = radiation therapy; CMF = cyclophosphamide, methotrexate, and 5-fluorouracil; $\mathrm{CEF}$ = cyclophosphamide, epirubicin and fluorouracil; CNF = cyclophosphamide, mitoxantrone and 5-fluorouracil; 5-FU = 5 fluorouracil; DDFS = distant disease free survival; DFS = disease free survival; OS = overall survival; RR = relative risk; $\mathrm{BC}$ = breast cancer

CAFt and CMF are no longer commonly used in the adjuvant setting for the treatment of breast cancer. Recently, anthracycline and taxane based cytotoxic regimens have been adopted as standard regimens for the adjuvant treatment of locally advanced and operable breast cancer. Ishitobi et al. investigated whether anthracycline based neoadjuvant-chemotherapy-induced neutropenia was related to survival in patients with operable breast cancer ${ }^{[8]}$. The authors retrospectively analyzed 103 breast cancer patients who were treated with neoadjuvant chemotherapy including 
epirubicin-based chemotherapy followed by docetaxel. Thirty-one patients (30\%) demonstrated neutropenia (defined as a neutrophil count less than $1.5 \times 10^{9} / \mathrm{L}$ ) during the epirubicin-based regimen. Patients without neutropenia showed a significantly $(p=0.004)$ lower 5 -year DDFS rate $(64 \%)$ than those with neutropenia $(97 \%)$. In addition, multivariate analysis showed that neutropenia was an independent prognostic factor for DDFS $(p=0.02)$. Notably, the dose per cycle, and the total dose of epirubicin did not differ between groups, and thus did not contribute to the differences seen in outcome.

In 2011, the proposed impact of chemotherapy induced neutropenia on survival in early stage breast cancer patients was explored when cyclophosphamide, epirubicin and fluorouracil (CEF) were used ${ }^{[7]}$. A total of 335 patients who had been treated with CEF were studied. Mild and severe neutropenia occurred in $42 \%$ and $11 \%$ of subjects respectively, while $53 \%$ did not experience neutropenia during treatment. The relative dose intensity was not significantly different between groups. Patients without evidence of neutropenia exhibited a lower 5-year OS rate (65\%) than those with mild neutropenia $(89 \%)(p<0.001)$ and severe neutropenia (84\%) $(p<0.033)$. According to a multivariate Cox model with time-varying covariates, HR of death were 0.434 (95\% CI 0.298-0.634; $p<0.001$ ) for patients with mild neutropenia, and 0.640 (95\% CI $0.42-0.975 ; p=0.038$ ) for those with severe neutropenia. Both parameters were independently associated with survival.

The only published trial that failed to show an association between chemotherapy induced neutropenia and survival in breast cancer patients was a small, retrospective study that included patients with operable primary breast cancer and loco-regional relapse ${ }^{[25]}$. Grade 4 leukopenia was defined as a leukocyte count $<1.0 \times 10^{9} / \mathrm{L}$, and was noted in only 9 (5\%) patients. Patients were assigned to low $\left(0.1-2.4 \times 10^{9} / \mathrm{L}\right)$ and high $\left(2.5-6.1 \times 10^{9} / \mathrm{L}\right)$ leukocyte count for the purpose of data analysis. In this small study, with significant limitations in methodology, 10 -year breast cancer specific survival was $51 \%$ in the low group and $66 \%$ for the high leukocyte count group $(p=0.23)$. The characteristics of the 7 trials exploring the impact of chemotherapy induced neutropenia on outcome in breast cancer patients are detailed in Table 1.

\subsection{Ovarian cancer}

Data regarding the impact of chemotherapy-induced neutropenia on outcome in patients with gynecologic malignancies is limited (Table 2). Rocconi et al published the first retrospective study investigating leukopenia and outcomes in patients with ovarian cancer ${ }^{[26]}$. A total of 255 patients with International Federation of Gynecologic Oncology (FIGO) stage 2-4 ovarian cancer, who received a total of 6 cycles of carboplatin-taxane based chemotherapy were included in the analysis. Neutropenia, defined as absolute neutrophil count $\leqslant 1000 / \mathrm{mm}^{3}$ occurred in 203 (80\%) patients at least once while receiving chemotherapy. Patients with neutropenia during treatment were similar to patients who never had neutropenia in regards to age, race, body mass index (BMI), stage, histology, grade, and debulking status. Neutropenic patients demonstrated improvements in progression free survival (PFS) (14 vs. 6 months; $p=0.01$ ), OS (45 vs. 29 months; $p=0.03$ ) and platinum sensitivity rates ( $69 \%$ vs. $44 \% ; p=0.001$ ). As the number of neutropenic episodes increased, improvements in PFS (range 6 to 17 months; $p=0.07$ ) and platinum sensitivity (range $44 \%$ to $90 \%$; $p=0.002$ ) were demonstrated. When stratified by debulking status, neutropenia conferred a survival advantage in suboptimally debulked patients, but only demonstrated marginal improvements in optimally debulked patients.

This study was followed by a retrospective review by Kim et al., where the impact of neutropenia on survival was explored in patients treated specifically with carboplatin and paclitaxel ${ }^{[10]}$. A total of 179 patients with stage $1 \mathrm{C}$ to 4 epithelial ovarian cancer were evaluated, with $75.4 \%$ experiencing at least one episode of neutropenia (defined as ANC of $<1000 / \mathrm{mm}^{3}$ ). The median duration of follow up was 51.5 months. The median PFS and OS of neutropenic patients were longer than those of non-neutropenic patients (43 vs. 22 months, and 67 vs. 56 months, respectively); but this did not meet statistical significance ( $p=0.26$ and 0.59 , respectively). In multivariate analysis relative neutropenia was not identified as an independent prognostic factor. 
Table 2. Trial characteristics: Chemotherapy-induced neutropenia in patients with ovarian cancer

\begin{tabular}{|c|c|c|c|c|c|c|c|c|}
\hline $\begin{array}{l}\text { Primary } \\
\text { Author }\end{array}$ & Year & Study Type & Stage & $\begin{array}{l}\text { Patient } \\
\text { Number } \\
\text { (n) }\end{array}$ & Setting & Treatment & Variable & End-Point \\
\hline $\begin{array}{l}\text { Rocconi et al. } \\
\text { [26] }\end{array}$ & 2008 & Retrospective & $\begin{array}{l}\text { Stage 2-4 } \\
\text { EOC }\end{array}$ & 255 & Adjuvant & $\begin{array}{l}\text { Carboplatin }+ \\
\text { paclitaxel/docetax } \\
\text { el }\end{array}$ & Neutropenia & $\begin{array}{l}\text { OS } \\
\text { Neutropenia: } 45 \\
\text { months } \\
\text { No neutropenia: } 29 \\
\text { months } \\
(p=0.03) \\
\text { PFS } \\
\text { Neutropenia: } 14 \\
\text { months } \\
\text { No neutropenia: } 6 \\
\text { months } \\
(p=0.01)\end{array}$ \\
\hline Kim et al. ${ }^{[10]}$ & 2010 & Retrospective & $\begin{array}{l}\text { Stage } \\
1 C-4 \\
\text { EOC }\end{array}$ & 179 & Adjuvant & $\begin{array}{l}\text { Carboplatin + } \\
\text { paclitaxel }\end{array}$ & $\begin{array}{l}\text { Neutropenia } \\
\text { (CTCAE) }\end{array}$ & $\begin{array}{l}\text { OS } \\
\text { Neutropenia: } 67 \\
\text { months } \\
\text { No neutropenia: } 56 \\
\text { months } \\
(p=0.59) \\
\text { PFS } \\
\text { Neutropenia: } 43 \\
\text { months } \\
\text { No neutropenia: } 22 \\
\text { months } \\
(p=0.26)\end{array}$ \\
\hline Lee et al. ${ }^{[27]}$ & 2011 & Retrospective & $\begin{array}{l}\text { Stage } \\
\text { IC-4 } \\
\text { EOC }\end{array}$ & 608 & Adjuvant & $\begin{array}{l}\text { Carboplatin + } \\
\text { paclitaxel/liposom } \\
\text { al doxorubicin }\end{array}$ & $\begin{array}{l}\text { Leukopenia } \\
\text { during cycle } 1\end{array}$ & $\begin{array}{l}\text { HR death }(95 \% \mathrm{CI}) \\
\text { Leukopenia: } 0.66(p= \\
0.01)\end{array}$ \\
\hline
\end{tabular}

PFS = progression free survival; OS = overall survival; DFS = disease free survival; HR = hazard ratio

Most recently, Lee et al. performed a retrospective study using prospectively collected data as part of the CALYPSO clinical trial ${ }^{[27]}$. Within this population, the investigators evaluated presence of leukopenia (nadir white blood cell $<4.0 \times 10^{9} / \mathrm{L}$ or severe infection) during cycle 1 of chemotherapy with PFS. Of 608 evaluable patients, $72 \%$ (carboplatin + paclitaxel (CP) $=70 \%$, carboplatin + pegylated liposomal doxorubicin (CPLD) $=73 \%$ ) had leukopenia. In the cohort of patients treated with CP, leukopenia was associated with an improvement in PFS (HR 0.66, $p=0.01$ ). Carboplatin-liposomal doxorubicin was more effective than CP in patients without leukopenia (HR 0.51, $p=0.001$ ), but not those experiencing leukopenia (HR 0.93, $p=0.54$; interaction $p=0.008$ ). Based on the above findings, the authors concluded that first-cycle leukopenia was prognostic for patients with ovarian cancer treated with CP.

\subsection{Cervical cancer}

The same association was explored in cervical cancer patients receiving concurrent chemo-radiation (Table 3) ${ }^{[28]}$. Kim et al. retrospectively studied 107 patients with squamous cell carcinoma of the cervix treated with carboplatin-paclitaxel concurrent chemo-radiotherapy following radical hysterectomy with pelvic lymph node dissection. The median duration of follow up was 37.5 months. Relative neutropenia was defined as an ANC of $<1000 / \mathrm{mm}^{3}$ at chemotherapy cycle nadir. Sixty-six patients experienced at least one episode of neutropenia during therapy. The mean DFS in the neutropenic group was greater than that seen in patients who did not experience neutropenia during treatment [62.5 months (95\% CI 58.1-66.9) vs. 57.6 months (95\% CI 51.0-67.2); $p=0.55$ ]. By subgroup analyses, the gain of DFS mainly originated from the group of patients with nodal metastases ( 61.5 months vs. 49.4 months; $p=0.033$ ).Treatment-induced neutropenia proved to be the only significant independent factor for recurrence in cervical cancer (HR 0.35; 95\% CI 0.13 - 0.96; $p=0.042)$. 
Table 3. Trial characteristics: Chemotherapy-induced neutropenia in patients with cervical cancer

\begin{tabular}{|c|c|c|c|c|c|c|c|c|}
\hline $\begin{array}{l}\text { Primary } \\
\text { Author }\end{array}$ & Year & Study Type & Stage & $\begin{array}{l}\text { Patient } \\
\text { Number } \\
\text { (n) }\end{array}$ & Setting & Treatment & Variable & End-Point \\
\hline $\begin{array}{l}\text { Kim et } \\
\text { al. }{ }^{[28]}\end{array}$ & 2009 & Retrospective & $\begin{array}{l}\text { Stage } \\
1 \mathrm{~B}-2 \mathrm{~B} \\
\text { cervical } \\
\text { CA }\end{array}$ & 107 & $\begin{array}{l}\text { Adjuvant } \\
\text { CCRT }\end{array}$ & $\begin{array}{l}\text { Carboplatin + } \\
\text { paclitaxel + XRT }\end{array}$ & $\begin{array}{l}\text { Relative } \\
\text { Neutropenia }\end{array}$ & $\begin{array}{l}\text { HR death }(95 \% \text { CI) } \\
\text { Neutropenia: } \\
0.35 \text { (0.13-0.96) }\end{array}$ \\
\hline
\end{tabular}

CCRT = concurrent chemo-radiotherapy; $\mathrm{HR}=$ hazard ratio; $\mathrm{CA}$ = cancer; $\mathrm{XRT}$ = radiation therapy

\section{Discussion}

Neutropenia due to cytotoxic chemotherapy is a common adverse event ${ }^{[12]}$. Historically, dose-finding phase 1 and 2 clinical trials are conducted in order to determine the optimal dose of cytotoxic chemotherapeutic agents. These trials, in general, are small in size making it impossible to investigate individual differences in drug metabolism. As detailed by Gurney et al. there are significant limitations to the use of body surface area (BSA) for dose determination ${ }^{[17,18]}$. This method does not account for the marked inter-patient variation in drug metabolism, reportedly 4-10 folds, which may be attributable to genetic polymorphisms. In addition, it is hypothesized that pharmacokinetics and drug sensitivity largely reflect individual genetic predispositions, and thus use of BSA based dosing may result in high blood levels and toxicity in some, while underdosing others ${ }^{[29]}$.This potential unexpected under-dosing may lead to reduced effectiveness of chemotherapy and subsequent treatment failure (Figure 1). A Swedish group, who adopted the method of dosing to myelosupression in the adjuvant treatment of breast cancer, illustrated a three-fold inter-patient range of cyclophosphamide dose $\left(450-1800 \mathrm{mg} / \mathrm{m}^{2}\right)$ and a four-fold range for epirubicin (38-120 $\left.\mathrm{mg} / \mathrm{m}^{2}\right)$. This is more in keeping with the known inter-patient variation in drug clearance for these drugs ${ }^{[18]}$.

Body Surface Area (BSA) Based

Figure 1. Within a population of patients, enhanced metabolizers and poor metabolizers may exist. Toxicity experienced during therapy (i.e. neutropenia) may identify a cohort of patients receiving appropriate dosing, translating into improved survival. Patients with enhanced drug metabolism may be inadvertently underdosed, with compromised outcome.

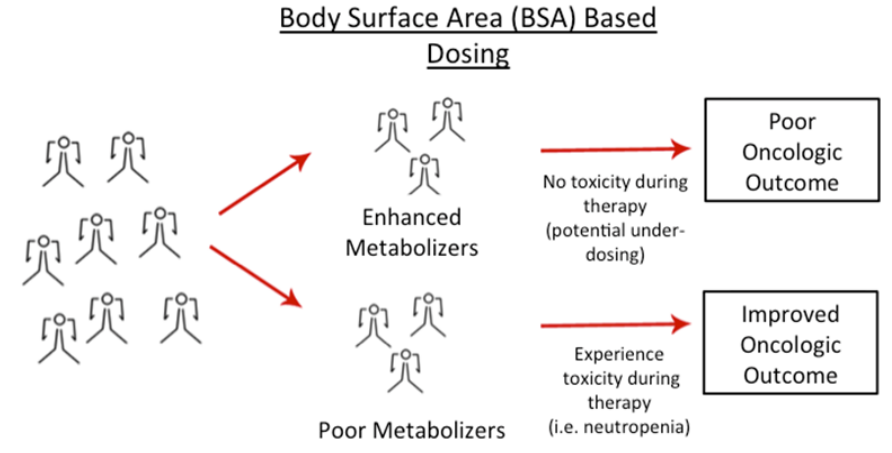

Attempts have been made to understand the mechanism by which chemotherapy induced neutropenia improves survival in cancer patients. Rocconi et al. hypothesized that chemotherapy induced neutropenia was a surrogate marker for "cancer stem cell” death (Figure 2) ${ }^{[26]}$. Cancer stem cells are a unique population of cancer cells with the ability for 1) self-renewal, 2) differentiation, 3) activation of anti-apoptotic pathways and 4) migration - metastasis. These cells exhibit relative resistance to apoptosis via radiation and cytotoxic agents. Thus, during conventional cytotoxic chemotherapy treatment, "differentiated" cancer cells are killed, with a relative sparing of cancer stem cells, which then regrow and shorten progression free survival. With increased neutropenia, it is postulated that a greater fractional kill of these cancer stem cells occurs, potentially improving survival.

In addition to the above, the impact of single nucleotide polymorphisms (SNPs) on survival and adverse events in patients with solid tumors has been studied. SNPs in DNA repair genes may adversely impact removal of DNA adducts, therefore 
augmenting the response to cytotoxic agents. This same phenomenon can result in neutropenia during therapy, and may potentially explain the relationship between chemotherapy induced neutropenia and survival. However, a large retrospective study evaluating specific genotype variants in DNA repair enzymes failed to show a significant association between 5 separate SNPs and neutropenia/survival in patients with advanced non-small-cell ling cancer ${ }^{[29]}$.

Figure 2. A) Conventional body surface area (BSA) based dosing may spare cancer stem cells leading to disease recurrence or metastasis. B) Conversely, neutropenia during therapy may indicate appropriate dosing, leading to cancer stem cell death and improved oncologic outcomes.

A)

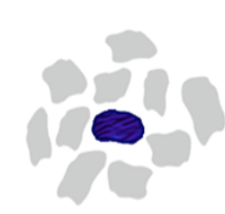

B)

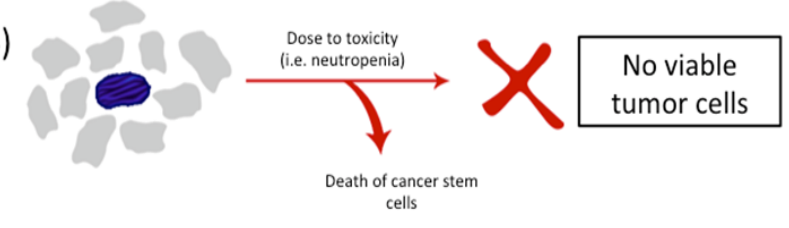

More recently, neutrophils have been implicated in the modification of the distant microenvironment prior to metastasis ${ }^{[30]}$. Kowanetz et al. described the accumulation of Ly6G+Ly6C+granulocytes in premetastaic tissues, facilitating colonization by cancer cells ${ }^{[30]}$. Furthermore, neutrophil elastase was shown to directly stimulate tumor cell proliferation in human and mouse lung adenocarcinomas ${ }^{[31]}$. This direct pro-tumoral role of neutrophils was also illustrated in elegant studies describing the impact of neutrophil associated matrix metalloprotease type 9 (MMP-9) on angiogenesis and early carcinogenesis ${ }^{[32]}$.

Neutropenia during chemotherapy has been associated with favorable clinical outcomes in breast, ovarian and cervical cancer, as detailed above. Of the 11 reviewed studies, 9 suggested that the occurrence of chemotherapy induced neutropenia was associated with improvement in outcomes, while its absence may be associated with underdosing. In support of this hypothesis, investigators have advocated using a toxicity-adjusted dose (TAD) to tailor the administration of cytotoxic chemotherapy ${ }^{[17,19]}$; monitoring of neutropenia (toxicity) during cytotoxic chemotherapy may lead to improved drug efficacy and survival. In 2009, Kaye et al. presented data, in abstract form, from a trial exploring intra-patient dose escalation of single agent carboplatin as first-line treatment for advanced ovarian cancer (SCOTROC4) at the ASCO annual meeting. Preliminary analysis failed to show an association between dose escalation, toxicity and outcome. Evaluation and publication of the finalized data set is pending.

In addition to cytotoxic chemotherapeutic agents, targeted therapies are currently being studied, both as single agents and in combination regimens for the treatment of gynecologic cancers. One of the best studied agents is the monoclonal anti-VEGF antibody, bevacizumab. Toxicities associated with bevacizumab include neutropenia, with previously published reports indicating increased incidence of neutropenia in subjects assigned to the bevacizumab containing arms of phase 2 and 3 clinical trials ${ }^{[33,34]}$. Recently, two large prospective, randomized, phase 3 clinical trials evaluating use of bevacizumab in ovarian cancer were published. Gynecologic Oncology Group (GOG) Protocol 218 and International Collaboration on Ovarian Neoplasms 7 (ICON7) reported significant improvements in progression free survival in patients treated with up-front and maintenance bevacizumab. Notably, grade 3 or greater neutropenia rates were higher in the bevacizumab containing arms, although this difference was not statistically significant (15 vs. 17\% - ICON7; 57.7 vs. $63.3 \%$ GOG-218) ${ }^{[15,16]}$. In addition to the above, OCEANS, GOG protocol 240, and GOG protocol 86P are exploring bevacizumab containing regiments in ovarian, cervical and endometrial cancer, respectively. Therefore, the implication of neutropenia on outcome during treatment with targeted therapies warrants exploration. 
In summary, the use and surveillance of chemotherapy-induced neutropenia may benefit a large proportion of the population currently receiving an unintentional under-dosing of cytotoxic chemotherapy. This TAD may guide more tailored chemotherapeutic dosing and improve outcomes in patients receiving treatment for both curative and palliative intent. To further assess the impact of neutropenia as a prognostic factor in gynecologic cancers, hypothesis-generating ancillary data studies should be conducted on prospectively collected patient data from completed phase 3 clinical trials in ovarian cancer, metastatic cervical cancer, and advanced/recurrent endometrial cancer. In patients from such trials with banked serum specimens, the opportunity to study surrogate markers of neutropenia, and the cascade that relates dose to response using SNPs, merits serious consideration. Additionally, the implication of variations in copy number and expression of drug metabolizing enzymes and transporters via microarray should be explored. Finally, prospective validation of these concepts, specifically, that neutropenia is indicative of response and is prognostic for PFS and OS, would require their inclusion as secondary and translational end-points in future gynecologic cancer trials.

\section{Acknowledgements}

The authors thank Rudy Ghaly for his kind assistance with the images contained within the manuscript.

\section{References}

[1] Siegel R, Naishadham D, Jemal A. Cancer statistics. 2012. CA Cancer J Clin. 2012; 62(1): 10-29. PMid:22237781 http://dx.doi.org/10.3322/caac.20138

[2] Shitara K, Matsuo K, Oze I, Mizota A, Kondo C, Nomura M, et al. Meta-analysis of neutropenia or leukopenia as a prognostic factor in patients with malignant disease undergoing chemotherapy. Cancer Chemother Pharmacol. 2011; 68(2): 301-7. PMid:22237781 http://dx.doi.org/10.1007/s00280-010-1487-6

[3] Banerji U, Ashley S, Coward J, Hughes S, Zee Y, Benepal T, et al. The association of chemotherapy induced neutropenia on treatment outcomes in small cell lung cancer. Lung Cancer. 2006; 54(3): 371-7. PMid:17049670 http://dx.doi.org/10.1016/j.lungcan.2006.08.001

[4] Cameron DA, Massie C, Kerr G, Leonard RC. Moderate neutropenia with adjuvant CMF confers improved survival in early breast cancer. Br J Cancer. 2003; 89(10): 1837-42. http://dx.doi.org/10.1038/sj.bjc.6601366

[5] Carpenter JT, Jr., Maddox WA, Laws HL, Wirtschafter DD, Soong SJ. Favorable factors in the adjuvant therapy of breast cancer. Cancer. 1982; 50(1): 18-23. http://dx.doi.org/10.1002/1097-0142(19820701)50:1<18::AID-CNCR2820500105>3.0.CO;2-J

[6] Di Maio M, Gridelli C, Gallo C, Shepherd F, Piantedosi FV, Cigolari S, et al. Chemotherapy-induced neutropenia and treatment efficacy in advanced non-small-cell lung cancer: a pooled analysis of three randomised trials. The lancet oncology. 2005; 6(9): 669-77. http://dx.doi.org/10.1016/S1470-2045(05)70255-2

[7] Han Y, Yu Z, Wen S, Zhang B, Cao X, Wang X. Prognostic value of chemotherapy-induced neutropenia in early-stage breast cancer. Breast Cancer Res Treat. 2011.

[8] Ishitobi M, Komoike Y, Motomura K, Koyama H, Inaji H. Prognostic significance of neutropenia on day one of anthracyclinebased neoadjuvant chemotherapy in operable breast cancer. Oncology. 2010; 78(3-4): 213-9. PMid:20424493 http://dx.doi.org/10.1159/000313702

[9] Brunetto AT, Carden CP, Myerson J, Faria AL, Ashley S, Popat S, et al. Modest reductions in dose intensity and drug-induced neutropenia have no major impact on survival of patients with non-small cell lung cancer treated with platinum-doublet chemotherapy. J Thorac Oncol. 2010; 5(9): 1397-403. PMid:20644495 http://dx.doi.org/10.1097/JTO.0b013e3181eba7f9

[10] Kim JJ, Park JY, Kim DY, Kim JH, Kim YM, Nam JH, et al. Is chemotherapy-induced neutropenia a prognostic factor in patients with ovarian cancer? Acta Obstet Gynecol Scand. 2010; 89(5): 623-8. PMid:20423275 http://dx.doi.org/10.3109/00016341003674913

[11] Smith TJ, Khatcheressian J, Lyman GH, Ozer H, Armitage JO, Balducci L, et al. 2006 update of recommendations for the use of white blood cell growth factors: an evidence-based clinical practice guideline. J Clin Oncol. 2006; 24(19): 3187-205. PMid:16682719 http://dx.doi.org/10.1200/JCO.2006.06.4451

[12] Aapro MS, Bohlius J, Cameron DA, Dal Lago L, Donnelly JP, Kearney N, et al. 2010 update of EORTC guidelines for the use of granulocyte-colony stimulating factor to reduce the incidence of chemotherapy-induced febrile neutropenia in adult patients with lymphoproliferative disorders and solid tumours. Eur J Cancer. 2011; 47(1): 8-32. PMid:21095116 http://dx.doi.org/10.1016/j.ejca.2010.10.013 
[13] Levine MN, Bramwell VH, Pritchard KI, Norris BD, Shepherd LE, Abu-Zahra H, et al. Randomized trial of intensive cyclophosphamide, epirubicin, and fluorouracil chemotherapy compared with cyclophosphamide, methotrexate, and fluorouracil in premenopausal women with node-positive breast cancer. National Cancer Institute of Canada Clinical Trials Group. J Clin Oncol. 1998; 16(8): 2651-8. PMid:9704715

[14] Ozols R, Bundy B, Greer B, Fowler J, Clarke-Pearson D, Burger R, et al. Phase III trial of carboplatin and paclitaxel compared with cisplatin and paclitaxel in patients with optimally resected stage III ovarian cancer: a Gynecologic Oncology Group study. J Clin Oncol. 2003; 21(17): 3194-200. PMid:12860964 http://dx.doi.org/10.1200/JCO.2003.02.153

[15] Burger RA, Brady MF, Bookman MA, Fleming GF, Monk BJ, Huang H, et al. Incorporation of bevacizumab in the primary treatment of ovarian cancer. N Engl J Med. 2011; 365(26): 2473-83. PMid:22204724 http://dx.doi.org/10.1056/NEJMoa1104390

[16] Perren TJ, Swart AM, Pfisterer J, Ledermann JA, Pujade-Lauraine E, Kristensen G, et al. A phase 3 trial of bevacizumab in ovarian cancer. N Engl J Med. 2011; 365(26): 2484-96. PMid:22204725 http://dx.doi.org/10.1056/NEJMoa1103799

[17] Gurney H. Dose calculation of anticancer drugs: a review of the current practice and introduction of an alternative. J Clin Oncol. 1996; 14(9): 2590-611. PMid:8823340

[18] Gurney H. How to calculate the dose of chemotherapy. Br J Cancer. 2002; 86(8): 1297-302. PMid:11953888 http://dx.doi.org/10.1038/sj.bjc.6600139

[19] Di Maio M, Gridelli C, Gallo C, Perrone F. Chemotherapy-induced neutropenia: a useful predictor of treatment efficacy? Nat Clin Pract Oncol. 2006; 3(3): 114-5. PMid:16520781 http://dx.doi.org/10.1038/ncponc0445

[20] Wood WC, Budman DR, Korzun AH, Cooper MR, Younger J, Hart RD, et al. Dose and dose intensity of adjuvant chemotherapy for stage II, node-positive breast carcinoma. N Engl J Med. 1994; 330(18): 1253-9. PMid:8080512 http://dx.doi.org/10.1056/NEJM199405053301801

[21] Saarto T, Blomqvist C, Rissanen P, Auvinen A, Elomaa I. Haematological toxicity: a marker of adjuvant chemotherapy efficacy in stage II and III breast cancer. Br J Cancer. 1997; 75(2): 301-5. PMid:9010042 http://dx.doi.org/10.1038/bjc.1997.49

[22] Henderson IC, Hayes DF, Gelman R. Dose-response in the treatment of breast cancer: a critical review. J Clin Oncol. 1988; 6(9): 1501-15. PMid:3047340

[23] Mayers C, Panzarella T, Tannock IF. Analysis of the prognostic effects of inclusion in a clinical trial and of myelosuppression on survival after adjuvant chemotherapy for breast carcinoma. Cancer. 2001; 91(12): 2246-57. PMid:10468293

http://dx.doi.org/10.1002/1097-0142(20010615)91:12<2246::AID-CNCR1255>3.0.CO;2-4

[24] Poikonen P, Saarto T, Lundin J, Joensuu H, Blomqvist C. Leucocyte nadir as a marker for chemotherapy efficacy in node-positive breast cancer treated with adjuvant CMF. Br J Cancer. 1999; 80(11): 1763-6. PMid:11413512 http://dx.doi.org/10.1038/sj.bjc.6690594

[25] Kumpulainen EJ, Hirvikoski PP, Johansson RT. Neutropenia during adjuvant chemotherapy of breast cancer is not a predictor of outcome. Acta Oncol. 2009; 48(8): 1204-6. PMid:19863230 http://dx.doi.org/10.3109/02841860902862537

[26] Rocconi RP, Matthews KS, Kemper MK, Hoskins KE, Barnes MN. Chemotherapy-related myelosuppression as a marker of survival in epithelial ovarian cancer patients. Gynecol Oncol. 2008; 108(2): 336-41. PMid:18006047 http://dx.doi.org/10.1016/j.ygyno.2007.10.012

[27] Lee CK, Gurney H, Brown C, Sorio R, Donadello N, Tulunay G, et al. Carboplatin-paclitaxel-induced leukopenia and neuropathy predict progression-free survival in recurrent ovarian cancer. Br J Cancer. 2011; 105(3): 360-5. PMid:21750553 http://dx.doi.org/10.1038/bjc.2011.256

[28] Kim YH, Chung HH, Kim JW, Park NH, Song YS, Kang SB. Prognostic significance of neutropenia during adjuvant concurrent chemoradiotherapy in early cervical cancer. J Gynecol Oncol. 2009; 20(3): 146-50. PMid:19809547 http://dx.doi.org/10.3802/jgo.2009.20.3.146

[29] Iranzo V, Sirera R, Bremnes RM, Blasco A, Jantus-Lewintre E, Taron M, et al. Chemotherapy-induced neutropenia does not correlate with DNA repair gene polymorphisms and treatment efficacy in advanced non-small-cell lung cancer patients. Clin Lung Cancer. 2011; 12(4): 224-30. PMid:21726821 http://dx.doi.org/10.1016/j.cllc.2011.03.023

[30] Kowanetz M, Wu X, Lee J, Tan M, Hagenbeek T, Qu X, et al. Granulocyte-colony stimulating factor promotes lung metastasis through mobilization of Ly6G+Ly6C+ granulocytes. Proc Natl Acad Sci U S A. 2010; 107(50): 21248-55. PMid:21081700 http://dx.doi.org/10.1073/pnas.1015855107

[31] Houghton AM, Rzymkiewicz DM, Ji H, Gregory AD, Egea EE, Metz HE, et al. Neutrophil elastase-mediated degradation of IRS-1 accelerates lung tumor growth. Nat Med. 2010; 16(2): 219-23. PMid:20081861 http://dx.doi.org/10.1038/nm.2084

[32] Nozawa H, Chiu C, Hanahan D. Infiltrating neutrophils mediate the initial angiogenic switch in a mouse model of multistage carcinogenesis. Proc Natl Acad Sci U S A. 2006; 103(33):12493-8. PMid:16891410 http://dx.doi.org/10.1073/pnas.0601807103

[33] Gressett SM, Shah SR. Intricacies of bevacizumab-induced toxicities and their management. Ann Pharmacother. 2009; 43(3): 490-501. PMid:19261963 http://dx.doi.org/10.1345/aph.1L426 
[34] Ranpura V, Hapani S, Wu S. Treatment-related mortality with bevacizumab in cancer patients: a meta-analysis. JAMA. 2011; 305(5): 487-94. PMid:21285426 http://dx.doi.org/10.1001/jama.2011.51 